\title{
A retrospective study on the effectiveness of Artificial Intelligence-based Clinical Decision Support System (AI-CDSS) to improve the incidence of hospital-related venous thromboembolism (VTE)
}

\author{
Shuai Zhou ${ }^{1 \#}$, Xudong Ma ${ }^{2 \#}$, Songyi Jiang ${ }^{3 \#}$, Xiaoyan Huang ${ }^{1,4}$, Yi You ${ }^{3}$, Hanbing Shang ${ }^{1}$, Yong Lu ${ }^{1,4}$ \\ ${ }^{1}$ Division of Medical Affairs, Ruijin Hospital, Shanghai Jiao Tong University School of Medicine, Shanghai, China; ${ }^{2}$ National Health Commission \\ of the People's Republic of China, Beijing, China; ${ }^{3}$ Beijing Huimei Technology Co., Ltd., Beijing, China; ${ }^{4}$ Department of Director's Office, Ruijin \\ Hospital, Luwan Branch, Shanghai Jiaotong University School of Medicine, Shanghai, China \\ Contributions: (I) Conception and design: S Zhou, Y Lu; (II) Administrative support: X Ma, Y Lu, H Shang; (III) Provision of study materials or \\ patients: Y Lu, H Shang, S Jiang; (IV) Collection and assembly of data: S Zhou, X Huang, S Jiang, Y You; (V) Data analysis and interpretation: X \\ Huang, S Zhou, X Ma, Y You; (VI) Manuscript writing: All authors; (VII) Final approval of manuscript: All authors. \\ \#These authors contributed equally to this work. \\ Correspondence to: Yong Lu. Director, Ruijin Hospital, Luwan Branch, Shanghai Jiao Tong University School of Medicine, Shanghai, China. \\ Email: 18917762053@163.com; Hanbing Shang. Department of Neurosurgery, Ruijin Hospital, Shanghai Jiao Tong University School of Medicine, \\ Shanghai, China. Email: Neuro_paper@126.com.
}

Background: Artificial intelligence technology is widely used in the medical industry. Our retrospective study evaluated the effectiveness of an AI-CDSS in improving the incidence of hospital-related VTE and the impact of anticoagulant drug use.

Methods: This study collected relevant data on adult patients over 18 years of age who are not discharged 24 hours, from January to July 2019 and from January to July 2020, the VTE high-risk department of Ruijin Hospital. Before and after using AI-CDSS, the incidence of hospital-related VTE and using anticoagulants were analyzed.

Results: Between January to July 2019 and January to July 2020, 3,565 and 4,423 adult patients over 18 years old were hospitalized in our hospital and were designed as a control group and intervention group, respectively (7,988 in total). Both groups had similar baseline characteristics. There were 4,716 (59.03\%) male patients, the mean age was $60.43 \pm 13.09$ years, and the mean stay was $7.56 \pm 7.76$ days. More than half of the patients $(4,605,57.58 \%)$ came from the respiratory. VTE events during hospitalization occurred in 41 patients; overall, 5.13/1,000 (41 episodes in 7,988 patients). Compared with the control group, before implementing AI-CDSS, the rate of VTE during hospitalization was reduced from 5.89/1,000 (21 episodes in 3,565 patients) to $4.75 / 1,000$ patients (20 episodes in 4,423 patients) (relative reduction of $19.35 \%$ ) in the intervention group. The use rate of anticoagulant drugs was increased from $19.97 \%(712 / 3,565)$ in the control group to $22.88 \%(1,012 / 4,423)$ in intervention group $[\mathrm{P}<0.01$, odds ratio (OR): 1.19 , 95 percent confidence interval (95\% CI) (1.07-1.32)], (relative 14.57\% increase). Poisson's regression results showed that department, age $\geq 75$ years [OR: $3.09,95 \% \mathrm{Cl}(1.45-6.33)$ ], duration of hospitalization [OR: $1.04,95 \%$ CI (1.03-1.05)], heart failure [OR: 5.13, 95\% CI (1.74-13.54)] and renal failure [OR: 3.60, 95\% CI (0.9011.34)] were high-risk factors for VTE events.

Conclusions: Implementing AI-CDSS can help clinicians identify hospitalized patients at increased VTE risk, take effective preventive measures, and improve clinicians' compliance with the American College of Chest Physicians (ACCP) guidelines.

Keywords: China; venous thromboembolism (VTE); a retrospective study; artificial intelligence-based clinical decision support system (AI-CDSS); hospitalization rate 
Submitted Dec 15, 2020. Accepted for publication Mar 24, 2021.

doi: 10.21037/atm-21-1093

View this article at: http://dx.doi.org/10.21037/atm-21-1093

\section{Introduction}

Venous thromboembolism (VTE), a disease of venous return disorder, refers to the abnormal coagulation of blood in the veins, which causes the blood vessels completely or incompletely blocked, including pulmonary embolism (PE) and deep vein thrombosis (DVT) formation, which are two clinical manifestations of the same disease at various stages and various parts (1). VTE affects $5 \%$ to $15 \%$ of patients hospitalized for medical or surgical symptoms (2), which has always been the primary cause of sudden death in hospitalized patients and an important direct cause of death from tumors and surgical cases $(3,4)$. With the increase of elderly patients and the acceleration of hospitalization turnover, the incidence of VTE has increased significantly. Studies have shown that $60 \%$ of VTE events occur during hospitalization or shortly after discharge, and the mortality rate of hospital-related VTE is much higher than the mortality rate of hospital infections. VTE occurring in the hospital poses a huge threat to the health of patients (5). Early prevention (6-10) of VTE has become a top priority that all medical institutions must face (11). However, because of many factors, including insufficient knowledge of the incidence and mortality of VTE, there are concerns about the risk of anticoagulation and bleeding in the standard course of treatment.

Further, there are also concerns about rising treatment costs and many others. The proportion of VTE norm assessment in China and even the Western Pacific region is significantly lower than in European and American countries, and the proportion of VTE norms and adequate full-course preventive medication is even lower (12). The results of the study, a multi-center cross-sectional study of VTE risk for inpatients in a tertiary hospital in China (13), showed that among the 13,609 hospitalized patients $(6,623$ medical patients, 6,986 surgery patients) in 60 research centers, $36.6 \%$ of hospitalized medical patients are highrisk groups of VTE, $53.4 \%$ of surgical inpatients are highrisk groups of VTE. With only $9 \%$ of those receiving VTE prophylaxis following the ACCP guidelines (the medical group, $6.0 \%$; the surgical group, $11.8 \%$ ), 9th edition. This result shows that the VTE prevention rate for inpatients in China is significantly lower than the multicenter Epidemiologic International Day results to evaluate patients at Risk for Venous Thromboembolism in the Acute Hospital Care Setting (ENDORSE) study (medical 43\%, surgery 55\%). Many medical institutions and hospitalized patients are still in a state of insufficient protection.

A retrospective controlled study was used to improve the effectiveness of AI-CDSS in improving the incidence of hospital-related VTE. The study clarified the role of AI-CDSS in reducing VTE incidence in hospitals and improving clinicians' compliance with VTE prevention and treatment guidelines. Further, it explored the impact of AI-CDSS on the incidence of anticoagulation-related major bleeding events, enhancing clinicians' awareness of VTE prevention and treatment to standardize the clinical management of VTE prevention and treatment. We present the following article in accordance with the STROBE reporting checklist (available at http://dx.doi.org/10.21037/ atm-21-1093).

\section{Methods}

\section{Study design}

This study, a retrospective study, evaluated hospital-acquired VTE's occurrence and the intensity of anticoagulant drugs before and after using AI-CDSS. We developed an AICDSS and connected it to Ruijin Hospital's electronic medical record system. When the patients entered the trial group, the AI-CDSS system was activated; the system automatically collected patient information, scored VTE, bleeding risk, and the wells every 6 hours or whenever the doctor entered the patient's electronic medical record system. When the assessment results showed that the patient was at increased risk, the system would give doctors corresponding preventive reminders.

According to the time when AI-CDSS was officially put into use in the clinical department, we identified 4,423 hospitalized patients who were at least 18 years of age and were not discharged in 24 hours from January to July 2020. Patients from the Trauma Surgery department, Respiratory, Emergency Intensive Care Unit (EICU), Medical Emergencies, Neurosurgery, Thoracic Surgery were included, as were patients monitored by AI-CDSS, which compared with the data of the same period in 2019. All procedures performed in this study involving human 
participants were in accordance with the Declaration of Helsinki (as revised in 2013). The study was approved by Shanghai Jiao Tong University School of Medicine, Ruijin Hospital ethics committee (approval No. 2020-164). Informed consent from participants was exempted by the ethics committee.

\section{Acceptance criteria}

Inclusion criteria: inpatients aged $\geq 18$ years came from 24 VTE high-risk departments where VTE incidence in 2019 was greater than $0.1 \%$ in Ruijin Hospital.

Exclusion criteria: hospitalized patients who met the following four conditions would not be included: (I) hospitalized patients were diagnosed with DVT or PE using the International Classification of Diseases, 10th Revision (ICD-10) at the time of admission; (II) had taken part in a similar clinical trial; (III) expected hospital stay <24 hours; (IV) full anticoagulation.

\section{Data collection}

The standard process of data collection is: in the first step, the AI-CDSS automatically retrieved the medical records of patients discharged from the hospital 24 hours daily at 0:00. The admission diagnosis had no DVT/PE, and the discharge diagnosis had DVT/PE, which was a recorded hospital-acquired VTE incident in the database. Simultaneously, the AI-CDSS automatically summarized the information of patients with DVT diagnosis in the B-ultrasound and venography reports of discharged patients. In the second step, the designated clinical experts would review the patient information list obtained in the first step one by one, including but not limited to review of medical records, communication with the doctor in charge, and telephone/face-to-face communication with the patient to find whether it was hospital-acquired VTE. In the last step, the database administrator entered the results obtained above into the database, and the data inspector regularly checked the incoming information.

\section{Study endpoints and study variables}

The primary endpoint of the study was diagnosed as a hospital-acquired VTE, which was defined as a patient who had no VTE-related diagnosis on admission but had a VTE-related diagnosis on discharge, or a patient who was judged as VTE by clinical experts through imaging examinations including ultrasound, CT angiography (CTA), etc. during the hospitalization. The information about patients' demographic characteristics, including age, sex, body mass index (BMI), admission department, LOS, in-hospital outcome, discharge diagnosis (VTE, surgery, tumor, diabetes, heart failure, hypertension, renal failure, fracture, chronic lung-related diseases), anticoagulant drug use was collected. In these analyses, patients were divided into a control group and intervention group according to AI-CDSS usage.

\section{Statistical analyses}

Baseline characteristics are presented as numbers (\%) for categorical data, means \pm SDs for normally distributed continuous data. Categorical variables are evaluated by the chi-square test or Fisher exact probability method. For continuous variables, used $t$-test or analysis of variance if they met normal distribution, and used rank-sum test if they did not meet normal distribution. Crude hospitalacquired VTE rates were calculated using the number of hospital-acquired VTE as the numerator, and the number of inpatients in 2019 (control group) and 2020 (intervention group) were found as the denominator. Statistical significance was set up at two-tailed $\mathrm{P}$ values $<0.05$. All statistical tests were performed by using $\mathrm{R}$ version 4.0.2.

\section{Results}

\section{Characteristics of the patients}

Between January to July 2019 and January to July 2020, 3,565 and 4,423 adult patients over 18 years old were hospitalized in our hospital and were designed as a control group and intervention group, respectively (7,988 in total). Both groups had similar baseline characteristics (Table 1). There were 4,716 (59.03\%) male patients, the mean age was $60.43 \pm 13.09$ years, and the mean stay was $7.56 \pm 7.76$ days. More than half of the patients $(4,605,57.58 \%)$ came from the respiratory. The most common coexisting conditions were cancer $(33.34 \%)$ [there were fewer hospitalized patients with cancer because of Corona Virus Disease 2019 (COVID-19) in intervention group], surgery (in 32.72\%), diabetes (in $10.30 \%$ ), hypertension (in $24.70 \%$ ), heart failure (in $0.95 \%$ ), chronic lung disease (in $4.47 \%$ ), renal failure (in $0.69 \%$ ), fracture (in $0.39 \%$ ).

Patients in the intervention group [median 63 (IQR 16) years] were older than those in the control group [median 
62 (IQR 15) years], but $80 \%$ of patients in both groups were concentrated between 41-74 years old. Compared with the control group, the duration of hospitalization was shorter in the intervention group. There was no significant difference in sex $(\mathrm{P}=0.592)$, diabetes $(\mathrm{P}=0.290)$, and fracture $(\mathrm{P}=0.507)$ between the two groups. Except for patients with surgery, there was a statistical difference in that the number of patients with cancer, hypertension, heart failure, chronic lung disease, renal failure in 2019 was more than in 2020, respectively (Table 1).

\section{Distribution of VTE events during hospitalization}

VTE events during hospitalization occurred in 41 patients; overall, 5.13/1,000 (41 episodes in 7,988 patients). The positive impact observed with using AI-CDSS was supported over time. Compared with the control group, before implementing AI-CDSS, the overall rate of VTE during hospitalization was reduced from 5.89/1,000 (21 episodes in 3,565 patients) to $4.75 / 1,000$ patients (20 episodes in 4,423 patients) (relative reduction of

Table 1 Baseline and demographic characteristic of the hospitalized patients

\begin{tabular}{|c|c|c|c|}
\hline Characteristic & Control group $(\mathrm{N}=3,565)$ & Intervention group $(\mathrm{N}=4,423)$ & $P$ value \\
\hline Trauma surgery & $195(5.47)$ & $271(6.13)$ & \\
\hline Respiratory & $2,113(59.27)$ & $2,492(56.34)$ & \\
\hline Emergency ICU & $20(0.56)$ & $23(0.52)$ & \\
\hline Neurosurgery & $523(14.67)$ & $611(13.81)$ & \\
\hline Thoracic surgery & $589(16.52)$ & $921(20.82)$ & \\
\hline Sex, n (\%) & & & 0.592 \\
\hline Male & $2,093(58.71)$ & $2,623(59.30)$ & \\
\hline $18-40$ & $282(7.91)$ & $431(9.75)$ & \\
\hline $41-60$ & $1,187(33.30)$ & $1,450(32.78)$ & \\
\hline $61-74$ & $1,706(47.85)$ & $2,113(47.77)$ & \\
\hline$\geq 75$ & $390(10.94)$ & $429(9.70)$ & \\
\hline Duration of hospitalization, median (IQR) & $6[4-9]$ & $6[3-9]$ & $<0.001$ \\
\hline $\mathrm{BMI}\left(\mathrm{kg} / \mathrm{m}^{2}\right)^{\star}$ & & & $<0.05$ \\
\hline Underweight/normal weight $(<25)$ & $2,149(66.74)$ & $2,692(69.47)$ & \\
\hline Overweight $(\geq 25)$ & $1,071(33.26)$ & $1,183(30.53)$ & \\
\hline Absent & $2,450(68.72)$ & $2,924(66.11)$ & \\
\hline
\end{tabular}

Table 1 (continued) 
Table 1 (continued)

\begin{tabular}{|c|c|c|c|}
\hline Characteristic & Control group $(\mathrm{N}=3,565)$ & Intervention group $(\mathrm{N}=4,423)$ & $P$ value \\
\hline Present & $353(9.90)$ & $470(10.63)$ & \\
\hline Absent & $3,212(90.10)$ & $3,953(89.37)$ & \\
\hline Hypertension, n (\%) & & & $<0.05$ \\
\hline Absent & $2,640(74.05)$ & 3,375 (76.31) & \\
\hline Heart failure, n (\%) & & & $<0.001$ \\
\hline Present & $51(1.43)$ & $25(0.57)$ & \\
\hline Absent & $3,514(98.57)$ & $4398(99.43)$ & \\
\hline Absent & 3,365 (94.39) & $4,266(96.45)$ & \\
\hline Renal failure, $\mathrm{n}(\%)$ & & & $<0.05$ \\
\hline Present & $34(0.95)$ & $21(0.47)$ & \\
\hline Absent & 3,531 (99.05) & 4,402 (99.53) & \\
\hline Fracture, n (\%) & & & 0.507 \\
\hline Present & $12(0.34)$ & $19(0.43)$ & \\
\hline Absent & 3,553 (99.66) & 4,404 (99.57) & \\
\hline
\end{tabular}

*, proportion of BMI missing outliers: 2019 (9.68\%) and 2020 (12.39\%); SD, standard deviation.

$19.35 \%)$ in the intervention group. Similar reduction rates were observed in respiratory [OR: $60.72,95 \% \mathrm{CI}$ (9.48-1,179.44)], age [OR: 5.09, 95\% CI (2.62-9.53)], duration of hospitalization [OR: 1.05, 95\% CI (1.04-1.06)], hypertension [OR: $2.15,95 \% \mathrm{CI}(1.14-3.99)]$, heart failure [OR: 22.87, 95\% CI (8.97-51.17)], renal failure [OR: 16.17, 95\% CI (4.70-42.47)] (Table 2).

From the perspective of the VTE anatomy, the inferior vena cava system embolism (57.14\%) and PE (33.33\%) frequently occurred in the control group, while the intervention group was mostly inferior vena cava system embolism (76.19\%) (Figure 1).

\section{VTE risk factors}

The control group's major VTE risk factor in hospitalized patients is the department, age $\geq 75$ years, hospitalization duration, cancer, diabetes, hypertension, and renal failure. Department, age $\geq$ re years, duration of hospitalization, BMI $\geq 25 \mathrm{~kg} / \mathrm{m}^{2}$, diabetes, and the fracture was the major VTE risk factor in the intervention group (Table 3).

Simultaneously, we also performed Poisson regression analysis to evaluate the risk factors of VTE by controlling potential confounding factors (department, age, duration of hospitalization, cancer, surgery, diabetes, hypertension, heart failure, renal failure, fracture), results indicating that department, age $\geq 75$ years [OR: $3.09,95 \% \mathrm{CI}(1.45-6.33)$ ], duration of hospitalization [OR: 1.04, 95\% CI (1.03-1.05)], heart failure [OR: 5.13, 95\% CI (1.74-13.54)] and renal failure [OR: 3.60, 95\% CI (0.90-11.34)] were high-risk factors for VTE events (Table 4).

\section{Using anticoagulant drugs}

We also accurately recorded using anticoagulant drugs in VTE patients, compared before and after implementing AICDSS, and found that the use rate of anticoagulant drugs was increased from $19.97 \%(712 / 3,565)$ in the control 
Table 2 AI-CDSS and the occurrence of VTE in hospitalized patients

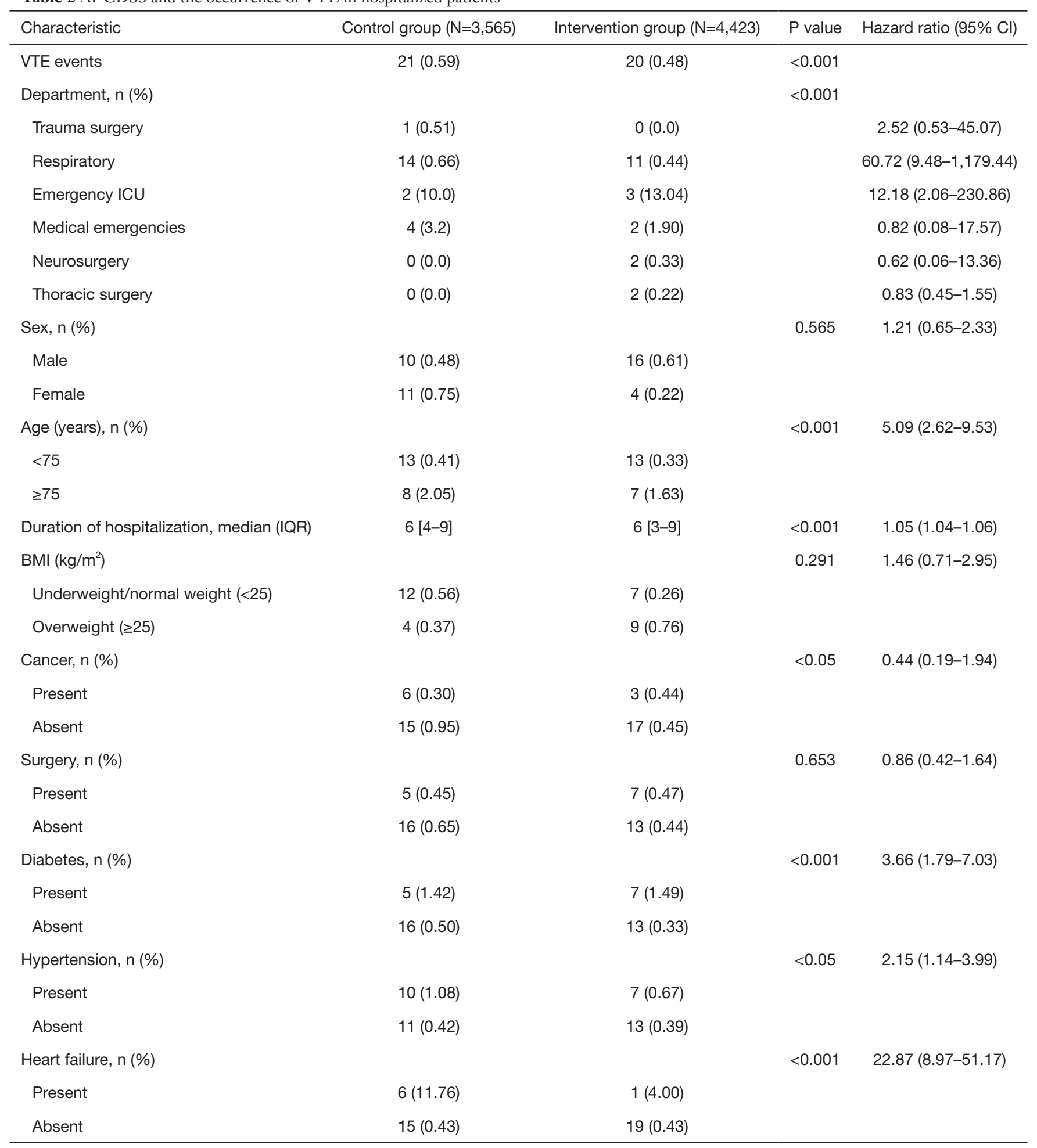

Table 2 (continued) 
Table 2 (continued)

\begin{tabular}{|c|c|c|c|c|}
\hline Characteristic & Control group $(\mathrm{N}=3,565)$ & Intervention group $(\mathrm{N}=4,423)$ & $P$ value & Hazard ratio $(95 \% \mathrm{Cl})$ \\
\hline Present & $2(1.00)$ & $2(1.27)$ & & \\
\hline Absent & $19(0.56)$ & $18(0.42)$ & & \\
\hline Renal failure, $\mathrm{n}(\%)$ & & & $<0.001$ & $16.17(4.70-42.47)$ \\
\hline Absent & $18(0.51)$ & $19(0.43)$ & & \\
\hline Fracture, n (\%) & & & $<0.001$ & $14.25(2.25-49.74)$ \\
\hline Present & $0(0.00)$ & $2(10.53)$ & & \\
\hline Absent & $21(0.59)$ & $18(0.41)$ & & \\
\hline
\end{tabular}

$\mathrm{Cl}$, confidence interval; AI-CDSS, Artificial Intelligence-based Clinical Decision Support System; VTE, venous thrombosis embolism.
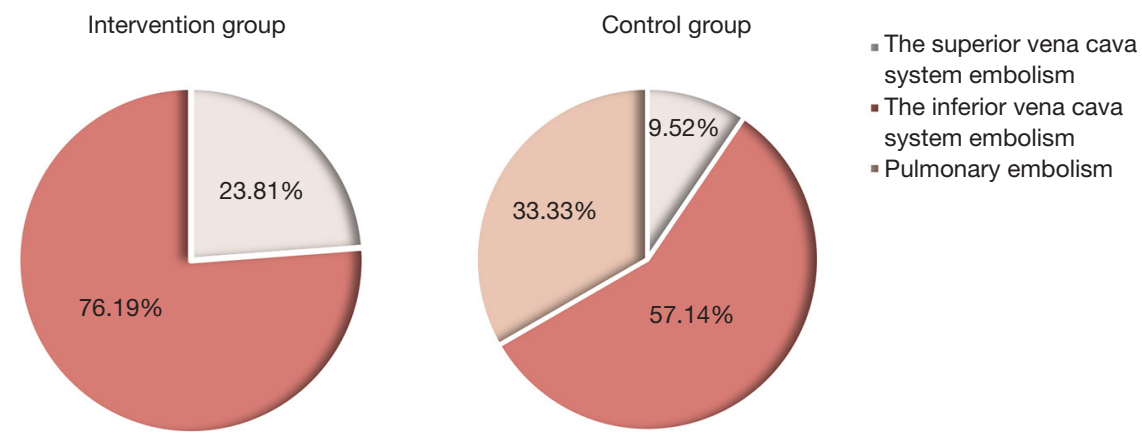

Figure 1 Statistics of anatomical parts of hospital-acquired VTE in the study. VTE, venous thromboembolism.

group to $22.88 \%(1,012 / 4,423)$ in the intervention group $[\mathrm{P}<0.01$, OR: $1.19,95 \%$ CI $(1.07-1.32)]$, (relative $14.57 \%$ increase). Similar increase rate was more pronounced in cancer patients $[\mathrm{P}<0.001$, OR: 4.86, 95\% CI $(4.03-5.867)]$ (Table 5).

\section{Discussion}

Implementing AI-CDSS can help clinicians identify hospitalized patients at increased VTE risk, which has also been confirmed in other similar studies (14). This is the first real-word study on the effectiveness of AI-CDSS to improve the incidence of hospital-related VTE in China. VTE has the characteristics of insidious onset, rapid onset, and high risk of death. Studies have shown that $60 \%$ of VTE events occur during hospitalization or shortly after discharge, a potential major hidden danger to medical quality and safety.
However, traditional manual diagnosis on data indicators consumes most labor and time and is also difficult to predict accurately. The study showed that the incidence of VTE was reduced by $19.35 \%$ after implementing AI-CDSS. This shows that AI-CDSS has a positive role in VTE risk management.

Evidence-based educational programs can be successful in increasing using prophylaxis by clinicians. Information tools for patient risk assessment can also improve physicians' use of different preventive therapies (15-17). ENDORSE used the American College of Chest Physicians (CHEST), 7 th edition $(9,18)$ guidelines, while the present study used CHEST, 9th edition (7-9), guidelines (which recommended the Caprini and Padua models for VTE risk evaluation). AI-CDSS in our study may have increased the accuracy of risk detection compared with ENDORSE (19). When the patients entered the trial group, the AI-CDSS system 
Table 3 VTE risk factors in hospitalized patients

\begin{tabular}{|c|c|}
\hline Risk factors & Values \\
\hline \multicolumn{2}{|l|}{ Control group $(\mathrm{N}=3,565)$} \\
\hline \multicolumn{2}{|l|}{ Department, $\mathrm{n}(\%)^{\star \star \star}$} \\
\hline Trauma Surgery & $1(0.51)$ \\
\hline Respiratory & $14(0.66)$ \\
\hline Emergency ICU & $2(10.00)$ \\
\hline Medical Emergencies & $4(3.20)$ \\
\hline Neurosurgery & $0(0.00)$ \\
\hline Thoracic Surgery & $0(0.00)$ \\
\hline Age $\geq 75$ years $^{\star \star \star}$ & $8(2.05)$ \\
\hline Duration of hospitalization, median (IQR) ${ }^{\star \star \star}$ & $6[4-9]$ \\
\hline Cancer* & $6(0.30)$ \\
\hline Diabetes* & $5(1.42)$ \\
\hline Hypertension* & $10(1.08)$ \\
\hline Renal failure ${ }^{\star \star *}$ & $3(8.82)$ \\
\hline \multicolumn{2}{|l|}{ Intervention group $(\mathrm{N}=4,423)$} \\
\hline \multicolumn{2}{|l|}{ Department, n (\%) } \\
\hline Trauma Surgery & $0(0.00)$ \\
\hline Respiratory & $11(0.44)$ \\
\hline Emergency ICU & $3(13.04)$ \\
\hline Medical Emergencies & $2(1.90)$ \\
\hline Neurosurgery & $2(0.33)$ \\
\hline Thoracic Surgery & $2(0.22)$ \\
\hline Age $\geq 75$ years* & $7(1.63)$ \\
\hline Duration of hospitalization, median (IQR) ${ }^{\star \star \star}$ & $6[4-9]$ \\
\hline $\mathrm{BMI} \geq 25 \mathrm{~kg} / \mathrm{m}^{2 *}$ & $9(0.76)$ \\
\hline Diabetes $^{\star \star}$ & $7(1.49)$ \\
\hline Fracture $^{\star \star}$ & $2(10.53)$ \\
\hline
\end{tabular}

Table 4 Poisson regression results of VTE risk factors in hospitalized patients

\begin{tabular}{|c|c|c|c|}
\hline Risk factors & $P$ value & OR & $\begin{array}{l}\text { Hazard ratio } \\
\qquad(95 \% \mathrm{Cl})\end{array}$ \\
\hline Department ${ }^{\star \star \star}$ & $<0.001$ & & \\
\hline Trauma Surgery & & 3.65 & $(0.74-65.99)$ \\
\hline Respiratory & & 6.76 & $(0.87-141.84)$ \\
\hline Emergency ICU & & 4.19 & $(0.65-81.71)$ \\
\hline Medical Emergencies & & 1.11 & $(0.11-24.04)$ \\
\hline Neurosurgery & & 0.76 & $(0.06-17.23)$ \\
\hline Age $\geq 75$ years $^{\star *}$ & $<0.01$ & 3.09 & $(1.45-6.33)$ \\
\hline Duration of hospitalization ${ }^{\star \star \star}$ & $<0.001$ & 1.04 & $(1.03-1.05)$ \\
\hline Heart failure ${ }^{\star \star}$ & $<0.01$ & 5.13 & $(1.74-13.54)$ \\
\hline Renal failure* & $<0.05$ & 3.60 & $(0.90-11.34)$ \\
\hline
\end{tabular}

was activated; the system automatically collected patient information and scored VTE, bleeding risk, and wells every 6 hours or whenever the doctor entered the patient's electronic medical record system. When the assessment results showed the patient was at increased risk, the system would give doctors corresponding preventive reminders: for VTE high-risk and Wells high-risk patients, AI-CDSS recommended intravenous B-ultrasound; for VTE highrisk and Wells low-risk patients, D-dimer test (DDI) was recommended. For VTE high-risk and bleeding low-risk patients, preventive anticoagulation or/and mechanical prevention was recommended. For VTE intermediaterisk, mechanical prevention or/and drug prevention was recommended. A warning would be given for VTE intermediate-high-risk and bleeding high-risk if a doctor prescribed anticoagulant drugs. For all patients prescribed mechanical prophylaxis, AI-CDSS determined whether the

Table 5 Using anticoagulant drugs

\begin{tabular}{lccrr}
\hline & Control group $(\mathrm{N}=3,565), \mathrm{n}(\%)$ & Intervention group $(\mathrm{N}=4,423), \mathrm{n}(\%)$ & $\mathrm{P}$ & $\mathrm{OR}(95 \% \mathrm{Cl})$ \\
\hline $\mathrm{N}$ & $712(19.97)$ & $1,012(22.88)$ & $<0.01$ & $1.19(1.07-1.32)$ \\
Cancer & $382(19.22)$ & $362(53.63)$ & $<0.001$ & $4.86(4.03-5.867)$ \\
\hline
\end{tabular}

Anticoagulant drug use intensity = anticoagulant drug consumption (various DDD) $\times 100 /$ (the number of patient days admitted in the same period). The number of patient days admitted in the same period $=$ the number of patients discharged in the same period $\times$ the average number of days in hospital in the same period. 
lower extremity ultrasound screening had been performed within 72 hours; if not, it reminded the doctor. If the ultrasound examination found DVT formation (including suspicious) and CT pulmonary angiography (CTPA) finds $\mathrm{PE}$ (including suspicious), AI-CDSS reminded the doctor paid attention via corporate WeChat. Unfortunately, the study is a retrospective study; it is impossible to compare specific interventions' effects. This will be further perfected in the succeeding study.

The study also found that the anticoagulant drugs use rate was $22.88 \%$ in the intervention group, which increased by $14.57 \%$ after implementing AI-CDSS.

Patients at risk of VTE were recommended for pharmacological thromboprophylaxis according to the ACCP guidelines $(9,20,21)$. A nationwide, multi-center, cross-sectional study of VTE prophylaxis in Chinese inpatients showed all proper VTE prophylaxis rates of 12.9\%; appropriate VTE prophylaxis rates implementing AI-CDSS were much higher than our results. These findings that AI-CDSS improved clinicians' compliance with the ACCP guidelines, thereby increasing the coagulant used. However, compared with ENDORSE and VOICE results, proper pharmacological VTE prophylaxis rates of inpatient were at $16-50.2 \%(19,22)$. This reflects insufficient awareness of VTE prophylaxis in Chinese physicians. Early identification, early diagnosis, and standardized treatment of VTE can effectively reduce the risk of VTE.

AI-CDSS moves VTE risk management and control forward and assesses the risk of VTE and bleeding from the patient's admission, and reminds clinicians to take effective preventive measures. This can significantly reduce patients' adverse consequences, hospitals' and doctors' medical risks, medical disputes, and medical health burdens. Simultaneously, to fill the gaps between the guidelines and clinical practice, to improve clinicians' awareness of VTE risk prevention and control, repeated physician education intervention by multiple media including forum, conference, lecture, video, brochure, WeChat public account (23).

Research risk control is reflected in anticoagulation treatment. Researchers will conduct publicity and education on patients and their families and judge whether they have bleeding tendencies with their symptoms, signs, and blood routines. If bleeding occurs, clinicians at once stop using low-molecular-weight heparin and have medical staff perform relevant treatments, including cold compress, puncture, aspiration for the Bleeding Academic Research Consortium (BARC) type 1, and intravenous injection protamine for the BARC type 2, type 3, type 4, type 5 . The professional clinicians will confirm every VTE event (including suspected cases) to ensure the research case's authenticity and reliability and the accuracy of the data quality, and each enrolled patient will experience two follow-ups. In the first follow-up, within 24 hours after the patient is admitted, AI-CDSS will automatically collect relevant data from the hospital information system to automatically complete the VTE risk assessment. In the second follow-up, when the patient is discharged, AI-CDSS collects relevant data from the hospital information system, and a qualified doctor confirms the data that needs to be confirmed by the clinician. No added medical activities are added during the whole research process, and AI-CDSS automatically collects all data, and the compliance of the research subjects is high.

\section{Acknowledgments}

Funding: This study was supported by the Fund provided by The Special Project of Integrated Traditional Chinese and Western Medicine in Shanghai General Hospital (ZHYY-ZXYJHZX-201901) and the Project of Continuous Improvement of Medical Quality Evidence-based Management (YLZLXZ-2020-008).

\section{Footnote}

Reporting Checklist: The authors have completed the STROBE reporting checklist. Available at http://dx.doi. org/10.21037/atm-21-1093

Data Sharing Statement: Available at http://dx.doi. org/10.21037/atm-21-1093

Conflicts of Interest: All authors have completed the ICMJE uniform disclosure form (available at http://dx.doi. org/10.21037/atm-21-1093). The authors have no conflicts of interest to declare.

Ethical Statement: The authors are accountable for all aspects of the work in ensuring that questions related to the accuracy or integrity of any part of the work are appropriately investigated and resolved. All procedures performed in this study involving human participants were in accordance with the Declaration of Helsinki (as revised in 2013). The study was approved by Shanghai Jiao Tong University School of Medicine, Ruijin Hospital ethics 
committee (approval No. 2020-164). Informed consent from participants was exempted by the ethics committee.

Open Access Statement: This is an Open Access article distributed in accordance with the Creative Commons Attribution-NonCommercial-NoDerivs 4.0 International License (CC BY-NC-ND 4.0), which permits the noncommercial replication and distribution of the article with the strict proviso that no changes or edits are made and the original work is properly cited (including links to both the formal publication through the relevant DOI and the license). See: https://creativecommons.org/licenses/by-nc-nd/4.0/.

\section{References}

1. Kearon C, Akl EA, Ornelas J, et al. Antithrombotic Therapy for VTE Disease: CHEST Guideline and Expert Panel Report. Chest 2016;149:315-52.

2. Samama MM, Cohen AT, Darmon JY, et al. A comparison of enoxaparin with placebo for the prevention of venous thromboembolism in acutely ill medical patients. Prophylaxis in Medical Patients with Enoxaparin Study Group. N Engl J Med 1999;341:793-800.

3. Yin C, Yuan S. Research progress in risk assessment of venous thromboembolism. International Journal of Orthopaedics 2014;35:77-80.

4. Heit JA, Spencer FA, White RH. The epidemiology of venous thromboembolism. J Thromb Thrombolysis 2016;41:3-14.

5. Bouée S, Emery C, Samson A, et al. Incidence of venous thromboembolism in France:a retrospective analysis of a national insurance claims database. Thromb J 2016;14:4.

6. Smith SB, Geske JB, Maguire JM, et al. Early Anticoagulation Is Associated With Reduced Mortality For Acute Pulmonary Embolism. Chest 2010;137:1382-90.

7. Falck-Ytter Y, Francis CW, Johanson NA, et al. Prevention of VTE in orthopedic surgery patients: Antithrombotic Therapy and Prevention of Thrombosis, 9th ed: American College of Chest Physicians Evidence-Based Clinical Practice Guidelines. Chest 2012;141:e278S-e325S.

8. Gould MK, Garcia DA, Wren SM, et al. Prevention of VTE in nonorthopedic surgical patients: Antithrombotic Therapy and Prevention of Thrombosis, 9th ed: American College of Chest Physicians Guidelines. Chest 2012;141:e227S-e277S.

9. Kahn SR, Lim W, Dunn AS, et al. Prevention of VTE in nonsurgical patients: Antithrombotic Therapy and Prevention of Thrombosis, 9th ed: American College of Chest Physicians Evidence-Based Clinical Practice Guidelines. Chest 2012;141:e195S-e226S.

10. Liew NC, Alemany GV, Angchaisuksiri P, et al. Asian venous thromboembolism guidelines: updated recommendations for the prevention of venous thromboembolism. Int Angiol 2017;36:1-20.

11. Jang MJ, Bang S-M, Oh D. Incidence of venous thromboembolism in Korea:from the Health Insurance Review and Assessment Service database. J Thromb Haemost 2011;9:85-91.

12. Yang Y, Liang L, Zhai Z, et al. Pulmonary Embolism Incidence and Fatality Trends in Chinese Hospitals from 1997 to 2008:A Multicenter Registration Study. PLoS One 2011;6:e26861.

13. Zhai Z, Kan Q, Li W, et al. Venous Thromboembolism Risk Profiles and Prophylaxis in Medical and Surgical Inpatients The Identification of Chinese Hospitalized Patients' Risk Profile for Venous Thromboembolism (DissolVE-2)—A Cross-sectional Study. Chest 2019;155:114-22.

14. Nils Kucher, Sophia Koo, Rene Quiroz, et al. Electronic Alerts to Prevent Venous Thromboembolism among Hospitalized Patients. N Engl J Med 2005;352:969-77.

15. Mosen D, Elliot CG, Egger MJ, et al. The effect of a computerized reminder system on the prevention of postoperative venous thromboembolism. Chest 2004;125:1635-41.

16. Samama MM, Dahl OE, Mismetti P, et al. An electronic tool for venous thromboembolism prevention in medical and surgical patients. Haematologica 2006;91:64-70.

17. Dexter PR, Perkins S, Overhage JM, et al. A computerized reminder system to increase the use of preventive care for hospitalized patients. N Engl J Med 2001;345:965-70.

18. Geerts WH, Pineo GF, Heit JA, et al. Prevention of venous thromboembolism: the Seventh ACCP Conference on Therapy. Chest 2004;126:338S-400S.

19. Cohen AT, Tapson VF, Bergmann JF, et al. Venous thromboembolism risk and prophylaxis in the acute hospital care setting (ENDORSE study): a multinational cross-sectional study. Lancet 2008;371:387-94.

20. Guyatt GH, Eikelboom JW, Gould MK, et al. Approach to outcome measurement in the prevention of thrombosis in surgical and medical patients: Antithrombotic Therapy and Prevention of Thrombosis, 9th ed: American College of Chest Physicians Evidence-Based Clinical Practice Guidelines. Chest 2012;141:e185S-e194S.

21. Lansberg MG, O'Donnell MJ, Khatri P, et al. Antithrombotic and thrombolytic therapy for ischemic 
stroke: Antithrombotic Therapy and Prevention of Thrombosis, 9th ed: American College of Chest Physicians Evidence-Based Clinical Practice Guidelines. Chest 2012;141:e601S-e636S.

22. Kahn SR, Panju A, Geerts W, et al. Multicenter evaluation of the use of venous thromboembolism prophylaxis in acutely ill medical patients in Canada. Thromb Res

Cite this article as: Zhou S, Ma X, Jiang S, Huang X, You Y, Shang H, Lu Y. A retrospective study on the effectiveness of Artificial Intelligence-based Clinical Decision Support System (AI-CDSS) to improve the incidence of hospital-related venous thromboembolism (VTE). Ann Transl Med 2021;9(6):491. doi: 10.21037/atm-21-1093
2007;119:145-55.

23. Wang H, Qu J, Lu Y, et al. The effect of physician educational intervention on venous thromboembolism pharmacological prophylaxis in medical inpatients from the respiratory department: a retrospective cohort study. Ann Palliat Med 2020;9:3966-75. 